\title{
PERAN STRATEGIS CHIEF INFORMATION OFFICER (CIO) DI PERGURUAN TINGGI DALAM MEMBANGUN COMPETITIVE ADVANTAGE
}

\author{
Mohamad Ali Murtadho ${ }^{1}$ \\ ${ }^{1}$ Program Studi Sistem Informasi Fakultas Teknik \\ Universitas Pesantren Tinggi Darul 'Ulum (Unipdu) Jombang \\ Kompleks Ponpes Darul 'Ulum Rejoso Peterongan Jombang 61481 \\ Email : ${ }^{1}$ ali_murtadho_net@yahoo.co.id
}

\begin{abstract}
ABSTRAK
Perguruan tinggi tergolong dalam industri quasi-commercial, selain memberikan pelayanan pendidikan kepada masyarakat, juga menerapkan prinsip-prinsip manajemen industri komersial untuk mendapatkan dana sebagai pendukung keberlangsungan hidup universitas. Karakteristik perguruan tinggi yang demikian itu, menjadikan teknologi informasi (TI) menjadi sangat penting. Adanya kegagalan dalam implementasi TI dalam Universitas akan dipandang negatif oleh banyak pihak. Karenanya, IT governance saat ini menjadi salah satu critical success factor (CSF) bagi para pemimpin dan mitra perguruan tinggi untuk mengoptimalkan peran IT dalam efektifitas peningkatan aset, capaian kinerja, sasaran, tujuan, visi dan visi organisasi. Sejalan dengan perubahan keberadaan fungsi TI dari level operasional menjadi strategis di dalam suatu organisasi, muncul pula suatu manajerial baru yang disebut sebagai Chief Information Officer (CIO). Keberadaan CIO untuk organisasi yang sangat menggantungkan aktivitas bisnisnya sehari-hari pada sistem informasi dan teknologi Informasi (SITI) merupakan suatu keharusan. Tanpa adanya fungsi strategis dari sistem dan teknologi informasi, perusahaan yang bersangkutan akan mengalami permasalahan yang sangat serius. Pertanyaan yang muncul kemudian adalah bagaimana karakteristik dan peranan TI di perguruan tinggi sehingga membutuhkan tata kelola yang baik dan bagaimana peran strategis $\mathrm{CIO}$ dalam organisasi. Tulisan ini berusaha menjawab kedua pertanyaan tersebut.

Kata kunci: IT governance, chief information officer (CIO), teknologi informasi (TI), sistem informasi dan teknologi informasi (SITI)
\end{abstract}

\begin{abstract}
Universities belong to the quasi-commercial industry, in addition to provide educational services to the community, also apply the principles of management of commercial industry to raise funds to support the survival of the university. Characteristics of such universities, making information technology (IT) becomes very important. The failure have occurred in the implementation of IT within the university would be viewed negatively by many. Therefore, IT governance is now a critical success factor one (CSF) for leaders and college partners to optimize the role of IT in increasing asset effectiveness, achievement of performance, goals, objectives, vision and the vision of the organization. In line with changes in the presence of IT functions from operational to strategic level within an organization, there are also some new managerial known as the Chief Information Officer (CIO). The existence of $\mathrm{CIO}$ for an organization that is dependent activities of dailybusiness in the information systems and information technology (SITI) is a must.Without the strategic function of the system and information technology, the company concerned will have a very serious problem. The question that arises thenis how the characteristics and role of IT in higher education and thus require good governance and how the CIO's strategic role within the organization. This article tries to answer both questions.
\end{abstract}

Key words: IT governance, chief information officer (CIO), information technology (IT), systems information and technology information (SITI)

\section{Pendahuluan}

Kegagalan Implementasi Teknologi Informasi (TI) dalam Business Process universitas (perguruan tinggi) bukan akibat faktor teknis namun lebih kepada permasalahan non-teknis (faktor manusia, proses dan organisasi kerja). (Curry , 2002). Karakteristik perguruan tinggi sebagai organisasi digolongkan ke dalam bentuk organisasi yang loosely coupled world's dimana hubungan antar bagian cukup renggang. Dalam bentuk organisasi seperti ini, anggotanya belajar dan berubah dengan cara imitasi. Semua akan berjalan dengan baik jika rasa saling percaya tumbuh, sehingga civitas akademika harus dipandang sebagai manusia dan bukan mesin produksi, dimana hubungan informal antar anggota organisasi menjadi sangat penting (Curry, 2002; Wachid, 2004).

Dari sudut pandang yang lain, Brokers (2003) dalam Wachid (2004) perguruan tinggi tergolong dalam industri quasi-commercial, selain memberikan pelayanan pendidikan kepada masyarakat, juga menerapkan prinsip- 
prinsip manajemen industri komersial untuk mendapatkan dana sebagai pendukung keberlangsungan hidup universitas. Karakteristik perguruan tinggi yang demikian itu, menjadikan TI menjadi sangat penting. Adanya kegagalan atau pernah terjadi kegagalan dalam implementasi TI dalam universitas akan dipandang negatif oleh banyak pihak (tim blueprint TI, 2010).

Teknologi Informasi menjadi semakin penting bagi organisasi, perguruan tinggi (dan organisasi lainnya) karena dapat memudahkan pelaksanaan proses bisnis dan meningkatkan keunggulan kompetitif. Melalui TI, proses bisnis dapat dilaksanakan lebih mudah, cepat, efisien, dan efektif. TI juga merawarkan banyak peluang kepada perguruan tinggi untuk meningkatian kinerja, mentransformasikan pelayanan, proses kerja, hubungan-hubungan kornunitas dan riset. Karenanya, IT governance saat ini menjadi salah satu critical success factor (CSF) bagi para pemimpin dan mitra perguruan tinggi untuk mengoptimalkan peran TI dalam efektifitas peningkatan aset, capaian kinerja, sasaran, tujuan, visi dan visi organisasi (Henderi, 2010).

Kompleksitas penerapan TI pada organisasi menimbulkan kesukaran pada berbagai level pemimpin dan stakeholder dalam memahami, membuat dan menerapkan IT governance di perguruan tinggi. Akibatnya manfaat penggunaan TI yang di dapatkan perguruan tinggi dirasakan belum sebanding dengan nilai investasi yang telah dikeluarkan. Inilah yang menyebabkan fenomena "productivity paradox", dimana investasi yang besar tidak menghasilkan manfaat yang besar (Brynjolfsson dan Hitt, 1998).

Banyak pihak yang menjadi resisten dalam implementasi TI, akibatnya transformasi business process yang diharapkan dengan TI berakselerasi dengan cepat justru akan mengalami kemandekan. Untuk mengatasi hal ini diperlukan peranan dan dorongan yang kuat dari pimpinan universitas atau Rektor dan organisasi pengelola TI yang dapat melakukan pengelolaan TI yang terarah, terstruktur dan selaras dengan kebutuhan organisasi. (blueprint IT,2010). Sejalan dengan perubahan keberadaan fungsi T.I dari level operasional menjadi strategis di dalam suatu organisasi, muncul pula suatu manajerial baru yang disebut sebagai Chief Information Officer (CIO). (McLeod dan Schell, 2004).

Keberadaan CIO untuk organisasi yang sangat menggantungkan aktivitas bisnisnya sehari-hari pada sistem informasi dan teknologi Informasi (SITI) merupakan suatu keharusan. Hal ini cukup beralasan mengingat harus adanya orang yang mewakili SITI dalam jajaran direksi. Tanpa adanya perwakilan tersebut, akan mustahil pencapaian fungsi strategis SITI akan tercapai. Dan tanpa adanya fungsi strategis dari sistem dan Teknologi informasi, perusahaan yang bersangkutan akan mengalami permasalahan yang sangat serius (Indrajit,1999).

\section{Model Tata keloloa TI Perguruan Tinggi}

Model struktur TI perguruan tinggi secara umum mempunyai enam kunci utama (Henderi 2010) yaitu:

1. Institutional Ownership. Bagian ini mempunyai hak dan tugas mengambil keputusan tingkat atas dalam rencana strategis TI dalam bisnis perguruan tinggi. Institutional Ownership juga menjalankan fungsi domain prioritas dan investasi yaitu memutuskan beberapa banyak dan dimana investasi TI akan difokuskan, termasuk menyetujui proyek-proyek TI dan pembenaran teknik lainnya.

2. Campus Direction, Coordination, Policy (information Technology Planning Board-Office of Information Technology). Bagian ini berhak dan menjalankan fungsi-fungsi yang lebih fokus kepada program aksi dan rekomendasi penerapan IT governance pada perguruan tinggi seperti yang telah ditetapkan dan diputuskan oleh Institutional Ownership.

3. Functional Planning Oversight. Mempunyai wewenang dan fungsi dalam menetapkan persyaratan bisnis produk TI yang akan dibeli atau aplikasi TI yang akan dikembangkan secara internal.

4. Areas of Emphasis (Student Integration, Research Leadership, Scholar Interaction, Increased Production, Community). Merupakan bentuk spesifik proses bisnis yang ada di perguruan tinggi serara umum.

5. Infrastructure (Common Infrastructure and Area Specific). Domain Ini mernpunyai hak dan fungsi sebagai pusat koordinasi layanan TI bagi lembaga perguruan tinggi. Termasuk didalamnya memberikan dasar bagi kemampuan organisasi TI, dibuat sebelum kebutuhan penggunaan yang tepat diketahui.

6. Technical Planning Oversight (Common System Group-Campus Computing Council). Berhak dan mempunyai tugas dalam menetapkan pilihan teknik untuk menuntun organisasi perguruan tinggi dalam mamenuhi kebutuhan bisnis organisasi.

\section{Sistem Informasi dan teknonolgi Informasi untuk Keunggulan kompetitif}

Penerapan tata kelola IT yang sesuai dengan prinsip, cara kerja, framework dan mekanisme implementasi IT governance pada perguruan tinggi diharapkan dapat meningkatkan performance, kemudahan, kecepatan, efesiensi, dan efektifitas kegiatan back office dan front office. Bahkan pada batas-batas tertentu, penerapan good IT governance dapat menawarkan dan membuka banyak peluang bagi perguruan tinggi dalam 
mentransformasikan pelayanan, pasar, proses kerja, hubungan belajar mengajar, melihat, berbagai kepentmgan stakeholder, dan dapat meningkatkan keunggulan kompetitif secara global. Karena itn perguruan tinggi hendanya merniliki IT govenance yang sama baiknya dengan corporate governance.

Untuk dapat memiliki good IT governance, perguruan tinggi harus memperhatikan dan menerapkan prinsip dasar dan framework IT governance, menetapkan dan memilih prototype dan mekanisme irnplementasi IT governance yang sesuai dengan spesifik kebutuhan perguruan tinggi.

Pada TI keunggulan kompetitif mengacu pada penggunaan informasi untuk mendapatkan pelanggan dipasar, dalam hal ini mahasiswa. Adapun sumber daya Informasi itu itu diantaranya adalah (1) Perangkat Keras Komputer, (2) Perangkat Lunak Informasi, (3) Para Spesialis Informasi , (4) Pemakai, (5) Fasilitas, (6) Data Base, (7) Informasi Sumber daya, dimana dibutuhkan leader untuk mengelola sumber daya informasi.

\section{Tugas Utama CIO}

CIO adalah orang yang menduduki jabatan sebagai kepala sistem informasi sebuah perusahaan atau organisasi. CIO dapat dikatakan sebagai direktur sistem dan teknologi informasi (Indrajit, 1999). CIO ini juga dapat dikatakan sebagai manajer jasa informasi yang menyumbangkan keahlian manajerialnya tidak hanya untuk memecahkan masalah yang berkaitan dengan sumberdaya informasi tetapi juga berbagai bidang lain dari operasi perusahaan.

Ralph Sprague beserta rekannya Barbara McNurlin menjabarkan bahwa setidaknya ada lima fungsi utama CIO di sebuah organisasi terutama perusahaan (Sprague et.al., 1993). Yaitu (a). Understand the business (b). Establish credibility of the system departmenture (c). Increase the technology maturity of the fim (d). Create a vision of the future and sellit (e). Implement and information system architect.

Lebih lanjut Indrajit (1999) juga menjabarkan kelima tugas sebagai berikut:

a. Memahami bisnis

Tugas pertama dan utama yang merupakan tanggung jawab eksekutif adalah mempelajari dan memahami secara menyeluruh dan mendetail bisnis yang digeluti perusahaan. Kalau dahulu manajemen inti cukup mempelajari semua komponen internal perusahaan (khususnya sehubungan dengan produk-produk atau jasajasa yang ditawarkan), saat ini hal tersebut tidaklah cukup. Persaingan yang begitu cepat dan lingkungan bisnis yang sangat dinamis mengharuskan eksekutif perusahaan untuk selalu memantau dan mempelajari aspek-aspek di luar perusahaan (eksternal) secara intens dan terus-menerus, terutama yang berkaitan dengan perilaku pasar (market) dan pelanggan. Setidak-tidaknya untuk dewasa ini ada tujuh cara yang terbukti efektif untuk mempelajari hal internal dan eksternal perusahaan.

Ketujuh cara tersebut adalah:

- Memiliki armada SDM yang secara berkala mempelajari keadaan pasar dan komponen eksternal lainnya;

- Mempelajari secara mendalam proses-proses penciptaan produk atau jasa yang ditawarkan perusahaan;

- Mengundang bagian-bagian lain dalam perusahaan untuk berdiskusi secara berkala;

- Menghadiri seminar-seminar yang berhubungan dengan industri terkait;

- Membaca secara aktif publikasi-publikasi yang berkaitan dengan produk, jasa, dan industri dimana perusahaan yang bersangkutan berada;

- Menjadi anggota forum-forum bisnis maupun akademis terkait; dan

- Menjalin komunikasi aktif dan konsisten dengan para manajer lini perusahaan.

b. Membangun citra divisi

Tugas kedua yang menjadi tanggung jawab seorang CIO adalah membangun kredibitilitas direktorat sistem informasi yang dipimpinnya. Hal ini sangat penting mengingat banyak sekali karyawan yang menilai bahwa penggunaan sistem informasi secara strategis merupakan ciri perusahaan di masa mendatang. Namun, direktorat sistem informasi yang ada harus dapat membuktikan bahwa aktivitias-aktivitas yang dilakukan saat ini adalah merupakan jalan atau jembatan menuju masa depan. Direktorat, departemen, atau divisi sistem informasi harus memiliki citra yang baik di mata fungsi-fungsi lain dalam perusahaan. Strategi yang paling efektif adalah dengan cara membantu para SDM di dalam perusahaan untuk meningkatkan kinerjanya melalui utilisasi teknologi informasi, karena hal inilah yang merupakan misi utama dari keberadaan sistem informasi di perusahaan. Pemberian pendidikan dan pelatihan kepada para pengguna (users) sistem informasi, mulai dari staf sampai dengan manajer eksekutif, merupakan salah satu cara lain untuk meningkatkan citra divisi sistem informasi. 
Dengan menghasilkan "produk-produk" yang terbukti dapat membantu para karyawan dalam melaksanakan aktivitas perkerjaannya sehari-hari, divisi sisten informasi akan dengan mudah mendapatkan kepercayaan dari fungsi-fungsi lain di organisasi untuk membawa mereka ke bentuk perusahaan masa depan.

c. Meningkatkan mutu penggunaan teknologi

Melihat bahwa keberadaan teknologi informasi ditujukan untuk meningkatkan kualitas kinerja SDM (employees empowerment), seorang CIO memiliki tugas untuk memasyarakatkan teknologi informasi agar dipergunakan secara aktif untuk para karyawan perusahaan. Selain pemberian program-program pelatihan (training) yang bersifat edukatif, diperlukan suatu strategi untuk membuat karyawan tertarik belajar lebih jauh dan memanfaatkan teknologi informasi yang ada. Caranya bisa beraneka ragam, mulai dari yang bersifat hiburan (entertainment) - seperti melalui permainan pada saat rekreasi perusahaan (company outing) sampai dengan yang sangat serius, seperti diadakannya workshop khusus. Tujuannya adalah agar para karyawan akrab dengan komputer (computer literate), sehingga selain dapat meningkatkan kualitas kerja mereka, inovasi-inovasi baru berupa ide-ide pengembangan di masa mendatang akan turut berpengaruh pada pengembangan sistem informasi di perusahaan.

d. Mencanangkan visi teknologi informasi

Tugas selanjutnya bagi seorang CIO adalah untuk menentukan visi perusahaan melalui pemanfaatan sistem informasi di masa mendatang. Seorang eksekutif senior yang baik, adalah yang selalu bersifat proaktif. Membantu perusahaan mencanangkan visinya di masa mendatang adalah salah satu contoh sikap proaktif yang harus dimasyarakatkan di kalangan perusahaan. Visi pemanfaatan sistem informasi merupakan bagian integral yang tak terpisahkan dari visi perusahaan secara umum.

Melihat bahwa abad sekarang dan mendatang adalah era yang sangat bergantung kepada informasi, peranan CIO dalam melihat masa depan perusahaan menempati posisi yang cukup dominan. Namun tugas CIO tidak hanya terbatas untuk merumuskan visi saja, namun yang bersangkutan harus dapat memasyarakatkan ide-ide yang ada ke seluruh jajaran manajemen dan staf (create a vision). Apalah artinya sebuah visi yang bagus tapi tidak ada seorang pun dari karyawan yang merasa perlu untuk mewujudkannya. Ada banyak teknik dan teori yang ditawarkan kepada manajemen untuk membantu merumuskan dan menjual visi kepada seluruh jajaran karyawan secara efektif. Hal ini sangat penting, karena visi merupakan akar dari seluruh aktivitas yang dilakukan oleh perusahaan dalam kegiatan bisnisnya setiap hari.

e. Pengembangan sistem informasi

Misi terakhir dari seorang CIO tentu saja membuat semua hal yang ada di atas menjadi nyata, yaitu merencanakan dan mengembangkan arsitektur sistem informasi perusahaan, yang terdiri dari komponenkomponen seperti software, hardware, brainware, proses dan prosedur, infrastruktur, standard, dan lain sebagainya. Secara berkesinambungan, seorang CIO harus dapat me-utilisasikan sistem informasi yang dimiliki perusahaan saat ini secara optimum, sejalan dengan rencana pengembangannya di masa mendatang. Suatu kali seorang praktisi manajemen mengatakan bahwa seorang CIO yang baik akan dapat "memanusiakan" karyawannya dengan cara memanfaatkan teknologi informasi untuk membantunya melaksanakan aktivitas pekerjaan sehari-hari.

\section{Peran strategis CIO}

Dalam The Role of The New CIO Meets Competitive Advantage (esa muchsi, 2011) yang dikutip dari Lutchen, Mark D. , "Managing IT as a Business", 2004, John Wiley \& Sons, Inc. - dalam peran baru CIO sangat beda dengan yang duhulu. Pada saat ini CIO dituntut harus memiliki segala aspek pengetahuan, berikut perbandingan antara peranan yang lama dengan yang baru. 


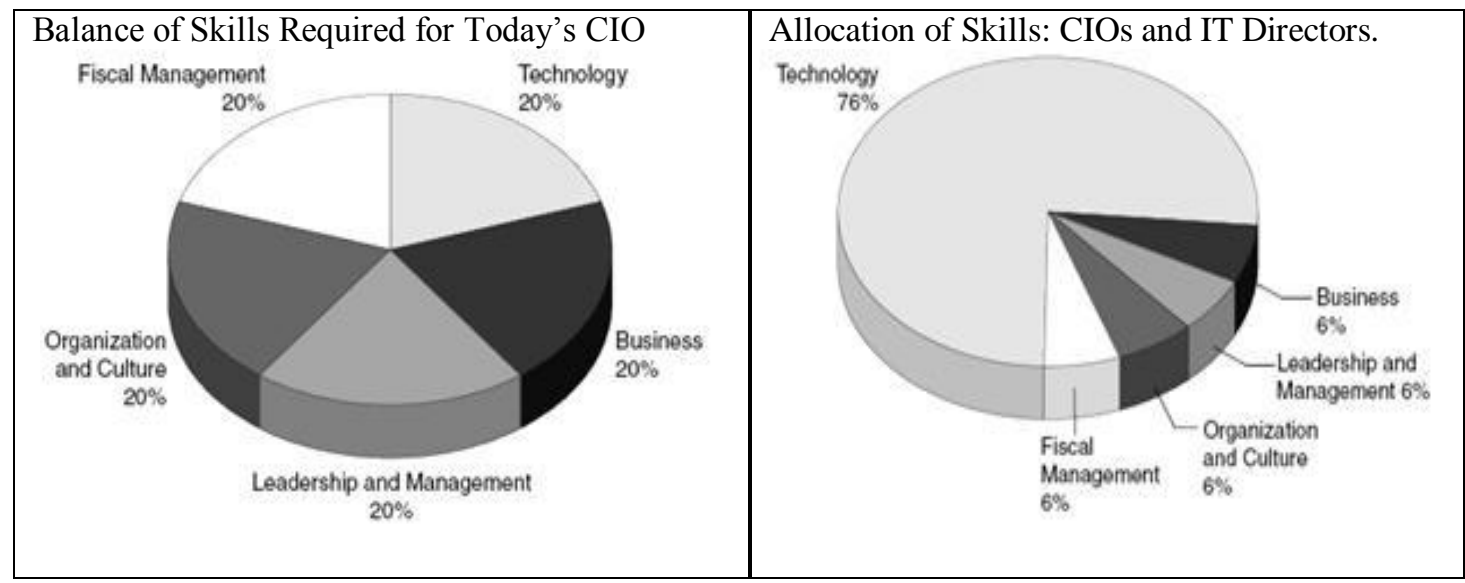

Gambar 1. Perbedaan Peran CIO Saat Ini Dengan Masa Lalu (Lutchen., 2004)

Hal tersebut akan membawa dampak langsung untuk mencapai tujuan dari perusahaan. Berdasarkan pengalaman, terkadang penerapan TI disebuah perusaan mengalami kegagalan dalam hal implementasi. Sebagai contoh, jika CIO ingin menerapkan sebuah sistem information teknologi pada perusahaan. Tentunya seorang CIO akan mempertimbangan dari sisi segala aspek, tidak hanya dari sisi teknologi. Berikut korelasi antara kemampuan CIO untuk bisa mensejajarkan antara strategi bisnis dengan strategi TI.

a. CIO harus mengetahui dari sisi keuangan (financial management - cost efficiency)

Bagaimana ROI dengan biaya yang dikeluarkan. Dengan diterapkannya IT dapat membantu peningkatan pendapatan perusahaan (organisasi) dan mengurangi biaya produksi.

b. CIO harus mengetahui dari sisi SDM (leadership and management - develop alliance)

Apakah SDM sudah siap dalam mengatasi perubahan dari kebiasaan dalam bekerja. CIO harus dapat mengkomunikasikan tentang rencana penerapan teknologi dengan bahasa yang mudah dimengerti oleh semua orang. Bukan bahasa tingkat tinggi yang biasa digunakan dalam berkomunikasi sesama orang IT. Seperti "internet service provider (ISP)", tidak semua orang tahu tentang bahasa itu. Sebagai contoh, jika koneksi internet putus tentunya akan ada komplain dari pegawai. Disini kita bisa menjelaskan "arus dari pusat pemberi akses internet sedang ada gangguan", tentunya hal demikian akan mempermudah seseorang dalam menyerap informasi sesungguhnya.

c. CIO harus mengetahui dari sisi teknologi (techlology - differentiate)

Teknologi apa yang cocok untuk dipakai dan diselaraskan agar satu sistem dengan sistem yang lainnya dapat saling berhubungan. Terkadang seorang CIO terpengaruh dengan teknologi terkini dan langsung menerapkannya tanpa memikirkan dampak lainnya, mungkin ketika satu sistem sudah diterapkan bisa berjalan tetapi sering terjadi kegagalan dalam menyatukan sistem satu dengan yang lainnya.

d. CIO harus mengetahui dari sisi bisnis (business - innovate)

Bisnis merupakan hal utama bagi suatu perusahaan. Seorang CIO dituntut harus sering berhubungan dengan CEO. Dari sisi bisnis sering dituntut untuk membuat inovasi produk, maka peran CIO adalah membuat solusi agar inovasi tersebut bisa selalu terjadi, mudah dan cepat dengan menggunakan bantuan teknologi informasi.

e. CIO harus mempunyai jiwa kepeminpinan dalam managemen (culture and organization-promote growth) Kemampuan berkomunikasi dalam menyampaikan suatu rencana dalam IT menjadi tolak ukur keberhasilan seorang CIO dalam menerapkan rencananya. Untuk bisa berkomunikasi disegala jajaran direksi perusahaan tidak mudah, maka pengetahuan tentang keuangan, bisnis, teknologi, managemen merupakan tolak ukur kemampuan dari CIO.

\section{Penutup}

Kegagalan Implementasi Teknologi Informasi/TI dalam Business Process Universitas (perguruan tinggi) bukan akibat faktor teknis namun lebih kepada permasalahan non-teknis (faktor manusia, proses dan organisasi kerja). perguruan tinggi tergolong dalam industri quasi-commercial, Selain memberikan pelayanan pendidikan kepada masyarakat, juga menerapkan prinsip-prinsip manajemen industri komersial untuk mendapatkan dana sebagai pendukung keberlangsungan hidup Universitas. Karakteristik perguruan tinggi yang demikian itu, menjadikan teknologi informasi menjadi sangat penting sehingga diperlukan pengelolaan TI yang terarah, terstruktur dan selaras dengan kebutuhan organisasi. Sejalan dengan perubahan keberadaan fungsi TI dari level operasional 
menjadi strategis di dalam suatu organisasi, muncul pula suatu manajerial baru yang disebut sebagai Chief Information Officer (CIO).

Fungsi utama CIO adalah (a). Understand the business (b). Establish credibility of the system departmenture (c). Increase the technology maturity of the fim (d). Create a vision of the future and sellit (e). Implement and information system architect. Selain kemampuan CIO dituntut untuk bisa mensejajarkan antara strategi bisnis dengan strategi TI yang dirangkum sebagai berikut:

Tabel 1. Kemampuan CIO

\begin{tabular}{|l|l|}
\hline Skills & Basic strategy in the business used of IT \\
\hline Technology & Differentiate \\
\hline Financial Management & Lower Cost \\
\hline Business & Innovate \\
\hline Leadership and Management & Develop Alliance \\
\hline Culture and organization & Promote Growth \\
\hline
\end{tabular}

\section{Daftar Pustaka}

Brookes, M., 2003. Higher Education: Marketing in A Quasi-Commercial Service Industry, International Journal of Nonprofit and Voluntary Sector Marketing, 8(2), 134-142.

Brynjolfsson, E., dan Hitt, E. L. M., 1998. Beyond the Productivity Paradox: Computers are the Catalyst for Bigger Changes. Communications of the ACM, 41(8), 49-55.

Curry, J. R., 2002. The Organizational Challenge: IT and Revolution in Higher Education, Educause review, April 40-48.

Esa, M., 2008. The Role of The New CIO Meets Competitive Advantage.

Henderi., 2010. IT governance : framework and prototype or higher education, Journal CCIT Vol.3 No. 2 Januari 2010.

Indrajit, Richardus Eko., 1999. Tugas Utama Chief Information Officer.

Lutchen, M. D., 2004. Managing IT as a Business, John Wiley \& Sons, Inc.

McLeod, J. R., dan George P. S., 2004. Management Information System $9^{\text {th }}$ edition. Practice Hall, Inc.

Sprague, and Barbara, C. M. N., 1993. Information Systems Management in Practice, Englewood cliffs. PrenticeHall, Inc: New Jersey.

Tim penyusun BPTI., 2010. Blue Print Teknologi Informasi 2010-201 UNMUL, Universitas Mulawarman.

Wachid, F., 2004. Peluang Dan Tantangan Pemanfaatan Teknologi Informasi Di Perguruan Tinggi, Jurnal media Informatika vol. 2 no. 1 Juni 2004 hal 11-22. 